\title{
Association between Stasis Dermatitis and Length of Stay in Heart Failure Hospitalizations
}

\author{
Ozge Kaya, Anıl Sahin', Hakki Kaya² \\ Dermatology Clinic, Canakkale State Hospital, ${ }^{2}$ Department of Cardiology, Canakkale Onsekiz Mart University Hospital, Canakkale, ${ }^{1}$ Cardiology Clinic, Antalya Training \\ and Research Hospital, Antalya, Turkey \\ ORCID: \\ Ozge Kaya: https://orcid.org/0000-0001-8062-1664 \\ Anıl Sahin: https://orcid.org/0000-0003-3416-5965 \\ Hakki Kaya: https://orcid.org/0000-0001-5230-635X
}

\section{Abstract}

Background: Stasis dermatitis (SD) is caused by venous hypertension that can be associated with peripheral congestion due to heart failure (HF). Length of stay (LOS) is the primary driver of HF hospitalization costs. Therefore, it is important to determine those patients who will have longer LOS. We aimed to investigate the relationship between the SD and LOS in HF patients. Methods: A total of 308 patients, who were hospitalized between January 2012 and January 2014 due to acute decompensated HF (ADHF) in our center, were evaluated in this retrospective observational cohort study. Patients' baseline clinical characteristics and presence of SD diagnosis within the past 3 months prior the HF hospitalization were assessed by a review of cardiology and dermatology clinics medical records. Results: A total of 237, acutely decompensated, HF patients were enrolled in the study. The median LOS was 5 days, and the mean LOS was $5.4 \pm 2$ days. Prolonged LOS was defined as LOS $>5$ days, and the patients were classified into two groups: Those with LOS $\leq 5$ days (Group I) and those with LOS $>5$ days (Group II, longer LOS). The presence of SD diagnosis was higher in Group II compared to patients in Group I $(22 \%$ vs. $46 \%, P<0.001)$. In the multivariate logistic regression model, presence of SD diagnosis, presence of moderate-to-severe tricuspid regurgitation, presence of atrial fibrillation, left atrial diameter, creatinine level, sodium level remained associated with longer LOS after adjustment for age, gender and for the variables found to be statistically significant in univariate analysis and correlated with LOS. Conclusions: This was the first time in the literature that a study demonstrated that the presence of SD was associated with an increased the risk of prolonged hospitalization independent of other factors in patients with reduced ejection fraction heart failure admitted for ADHF.

Keywords: Acute heart failure, congestion, length of stay, stasis dermatitis

\section{INTRODUCTION}

Acute decompensated heart failure (ADHF), that can be defined as the sudden initiation or rapid worsening of heart failure (HF) symptoms and results, is a complex clinical syndrome with high mortality and morbidity. ${ }^{[1]}$ Length of stay (LOS) of patients who hospitalized due to acute HF has been shown to be affected by many factors such as patient compliance with treatment, accompanying comorbidities, HF stages, functional capacities, and etiology of HF. ${ }^{[2-4]}$ It is important to establish the factors related to prolonged LOS in

Received: 05-03-2020 Revised: 24-03-2020 Accepted: 29-03-2020

Published Online: 11-06-2020

\begin{tabular}{|l|l|}
\hline \multicolumn{3}{c|}{ Access this article online } \\
\hline Quick Response Code: & Website: \\
& \\
http://www.ijcva.com
\end{tabular}

patients with HF since prolonged LOS pose additional risks to the patient and lead to increases in health expense. ${ }^{[5]}$

Stasis dermatitis (SD) is characterized by poorly demarcated erythematous and eczematous patches and plaques of the lower legs, classically involving the medial malleolus. SD is caused by venous hypertension (HT) that can be associated with only venous insufficiency or concomitant peripheral congestion due

Address for correspondence: Dr. Hakki Kaya, Department of Cardiology, Canakkale Onsekiz Mart University Hospital, Canakkale, Turkey. E-mail: drhakkikaya84@gmail.com

This is an open access journal, and articles are distributed under the terms of the Creative Commons Attribution-NonCommercial-ShareAlike 4.0 License, which allows others to remix, tweak, and build upon the work non-commercially, as long as appropriate credit is given and the new creations are licensed under the identical terms.

For reprints contact: WKHLRPMedknow_reprints@wolterskluwer.com

How to cite this article: Kaya O, Sahin A, Kaya H. Association between stasis dermatitis and length of stay in heart failure hospitalizations. Int $\mathrm{J}$ Cardiovasc Acad 2020;6:80-5. 
to HF. ${ }^{[6]}$ We thought that SD, which is a pathology that we see quite often during our daily clinical practice in patients with stasis in their lower extremities and is thought to develop as a result of venous HT, may be associated with prolonged LOS, and for the first time in the literature, we aimed to evaluate the relationship of SD, which we think may be an indicator of venous HT, with LOS of HF patients.

\section{Methods}

A total of 308 patients, who were hospitalized between January 2012 and January 2014 due to ADHF in our center, were evaluated in this retrospective observational cohort study. Patients' age; gender; comorbidities, such as diabetes mellitus (DM), HT, atrial fibrillation (AF); laboratory and echocardiographic results, previous medications and presence of SD diagnosis within the past 3 months prior the HF hospitalization were assessed by a review of hospital medical records. Four patients with previous diagnoses of malignancies, four patients with previous diagnoses of cirrhotic hepatic disease, 17 patients with acute coronary syndrome (ACS), nine patients with acute de novo HF (first attack), 14 patients with cardiogenic shock requiring intravenous inotrope, 15 patients with known lower extremity venous insufficiency, eight patients with a different diagnosis of dermatitis other than SD with lower extremity involvement [Figure 1]. The study was approved by the local ethics committee.

Decompensations were diagnosed based on a combination of the presence of a recent deterioration of symptoms and signs of HF, as suggested in guidelines. ${ }^{[7,8]}$ LOS was calculated as an overall in-hospital stay.

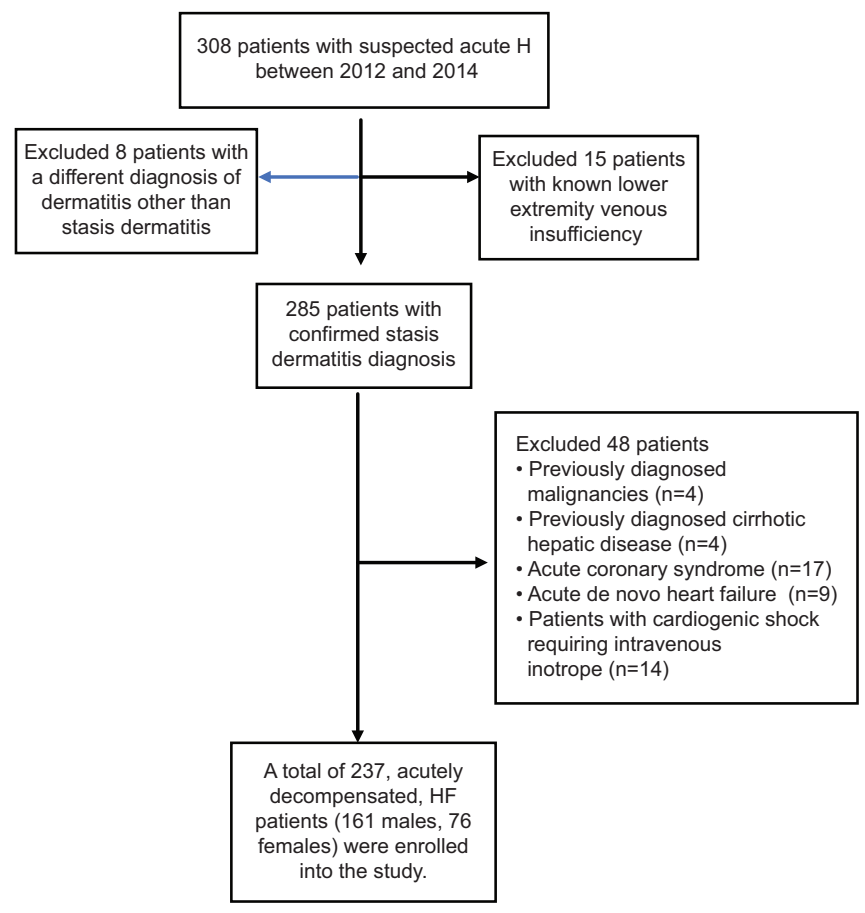

Figure 1: Patient flow chart
SD was diagnosed and recorded on hospital files by a dermatologist. The presence of characteristic dermatologic changes includes bilateral erythematous, scaly, and slightly discolored papules and plaques on the lower legs were used for diagnosis. ${ }^{[9]}$

Echocardiographic examinations were undertaken by experienced echocardiographers through the Vivid 7 system (GE Medical System) with 2.5-5 Mhz probes. The ejection fraction (EF) was calculated using the Modified Simpson method, in line with the most recent guidelines. ${ }^{[10]}$ Chamber sizes were defined according to recent guidelines. ${ }^{[10]}$ Systolic pulmonary artery pressure (SPAP) was calculated using the peak velocity of tricuspid regurgitation (TR) and estimated right atrial pressure. Valvular regurgitations were graded into two categories (moderate to severe or not moderate to severe) through a combination of color flow jet Doppler signal intensity, vena contracta width according to guideline recommendations. ${ }^{[11]}$

\section{Statistical analysis}

The Kolmogorov-Smirnov test was used to verify the normality of the distribution of continuous variables. Continuous variables were expressed as mean \pm standard deviation or median (minimum-maximum) in the presence of abnormal distribution, and categorical variables as percentages. Independent parameters were compared through an independent sample $t$-test, and if there was no normal distribution, through Mann-Whitney U-test with median. Categorical data were evaluated by the Chi-square test as appropriate. Correlation was evaluated using the Spearman correlation test. We used a univariate analysis to quantify the association of variables with prolonged LOS. Variables that were statistically significant in the univariate analysis and potential other confounders were used in a multivariate logistic regression model with forward stepwise method to determine the independent prognostic factors for prolonged LOS. All statistical procedures were performed using SPSS software version 14.0 (SPSS Inc., Chicago, IL, USA). A $P=0.05$ was considered as statistically significant.

\section{RESULTS}

A total of 237, acutely decompensated, HF patients (161 males and 76 females) were enrolled in the study. The median LOS was 5 days, and the mean LOS was $5.4 \pm 2$ days, ranging from 2 to 15 days. Prolonged LOS was defined as $\operatorname{LOS}>5$ days, and the patients were classified into two groups: Those with LOS $\leq$ S5 days (Group I) and those with LOS $>5$ days (Group II, longer LOS). The mean age was $68 \pm 11$ years, and mean EF was $32 \% \pm 7 \%$. Table 1 presents the baseline clinical characteristics of the patients in terms of their LOS. Patients in Group II had higher left atrial (LA) diameter, SPAP, blood urea nitrogen (BUN), creatinine levels and they had lower hemoglobin and sodium levels than the patients in Group I. The presence of SD diagnosis was higher in Group II compared to patients in Group I (46\% vs. 22\%, 
Table 1: Baseline clinical characteristics, laboratory, and echocardiographic parameters and preadmission medications of the patients in terms of their length of stay

\begin{tabular}{|c|c|c|c|}
\hline Characteristics & LOS $\leq 5$ days (Group I) $(n=135), n(\%)$ & LOS $>5$ days (Group II) $(n=102), n(\%)$ & $P$ \\
\hline Age (years) & $68 \pm 11$ & $69 \pm 11$ & 0.231 \\
\hline Female & $44(33)$ & $32(31)$ & 0.842 \\
\hline Hypertension & $76(56)$ & $55(53)$ & 0.716 \\
\hline Diabetes mellitus & $33(24)$ & $36(35)$ & 0.069 \\
\hline Atrial fibrillation & $40(30)$ & $56(55)$ & $<0.001$ \\
\hline \multicolumn{4}{|l|}{ Laboratory parameters } \\
\hline BUN (mg/dl) & $21(8-103)$ & $30(6-114)$ & $<0.001$ \\
\hline Creatinine (mg/dl) & $1.2(0.5-5.7)$ & $1.7(0.5-6.3)$ & $<0.001$ \\
\hline Sodium $(\mathrm{mmol} / \mathrm{L})$ & $134 \pm 3$ & $131 \pm 5$ & $<0.001$ \\
\hline Potassium (mmol/L) & $4.5(3.3-6.4)$ & $4.5(3.1-6.4)$ & 0.927 \\
\hline Hemoglobin $(\mathrm{g} / \mathrm{dl})$ & $13 \pm 2$ & $12 \pm 2$ & 0.010 \\
\hline $\mathrm{BNP}(\mathrm{pg} / \mathrm{ml})$ & $1452(1000-4256)$ & $1456(1054-8898)$ & 0.075 \\
\hline \multicolumn{4}{|l|}{ Echocardiographic parameters } \\
\hline LA diameter (mm) & $44 \pm 7$ & $48 \pm 8$ & $<0.001$ \\
\hline LV diastolic diameter $(\mathrm{mm})$ & $53 \pm 8$ & $54 \pm 8$ & 0.540 \\
\hline $\mathrm{EF}(\%)$ & $33 \pm 7$ & $31 \pm 8$ & 0.116 \\
\hline RV dilatation & $43(32)$ & $54(53)$ & 0.001 \\
\hline SPAP (mmHg) & $36 \pm 14$ & $43 \pm 14$ & $<0.001$ \\
\hline Moderate-to-severe TR & $38(28)$ & $64(63)$ & $<0.001$ \\
\hline Moderate-to-severe MR & $28(21)$ & $44(43)$ & $<0.001$ \\
\hline \multicolumn{4}{|l|}{ Preadmission medications } \\
\hline Usage of ACEI/ARB & $111(82)$ & $85(83)$ & 0.960 \\
\hline Usage of MRA & $48(36)$ & $37(36)$ & 0.909 \\
\hline Usage of beta blocker & $117(87)$ & $85(83)$ & 0.591 \\
\hline Usage of diuretics & $107(79)$ & $82(80)$ & 0.830 \\
\hline Presence of stasis dermatitis diagnosis & $29(22)$ & $47(46)$ & $<0.001$ \\
\hline
\end{tabular}

BUN: Blood urea nitrogen, LOS: Length of stay, BNP: B-type natriuretic peptide, SPAP: Systolic pulmonary artery pressure, LA: Left atrium, LV: Left ventricle, RV: Right ventricle, MR: Mitral regurgitation, TR: Tricuspid regurgitation, ACEI: Angiotensinogen converting enzyme inhibitor, ARB: Angiotensin receptor blocker, MRA: Mineralocorticoid receptor antagonist, EF: Ejection fraction

$P<0.001)$ and the ratios of patients with AF, patients with right ventricle (RV) dilatation, patients with moderate-to-severe TR and mitral regurgitation (MR) were higher in Group II than Group I [Table 1]. LOS was positively correlated with SPAP, LA diameter, BUN, creatinine, and B-type natriuretic peptide (BNP) levels and associated with the presence of SD diagnosis, AF, moderate-to-severe TR and moderate-to-severe MR. LOS was negatively correlated with the hemoglobin, sodium levels, and EF [Table 2].

The results of the univariate and multivariate logistic regression analyses for the prolonged LOS are summarized in Table 3. According to univariate analysis, older age, presence of SD diagnosis, presence of AF, presence of moderate-to-severe MR, presence of moderate-to-severe TR, higher BUN levels, higher creatinine levels, higher BNP levels, higher SPAP, higher LA diameter, lower hemoglobin, and lower sodium levels were significantly associated with an increased risk of prolonged LOS. In the multivariate logistic regression model, presence of SD diagnosis (odds ratio $[\mathrm{OR}]=23.832,95 \%$ confidence interval [CI]: 7.217-78.696, $P<0.001)$, presence of moderate to severe TR $(\mathrm{OR}=4.413,95 \% \mathrm{CI}: 1.361-14.314, P=0.013)$, presence of AF $(\mathrm{OR}=3.215,95 \% \mathrm{CI}: 1.123-9.204, P=0.030)$, LA diameter $(\mathrm{OR}=1.089,95 \% \mathrm{CI}: 1.016-1.168, P=0.016)$,

\begin{tabular}{lcc}
\hline $\begin{array}{l}\text { Table 2: Spearman correlation coefficients for the length } \\
\text { of stay }\end{array}$ & $\boldsymbol{r}$ & $\boldsymbol{P}$ \\
\hline LOS & 0.291 & $<0.001$ \\
\hline Presence of stasis dermatitis diagnosis & 0.174 & 0.015 \\
BNP & 0.354 & $<0.001$ \\
Presence of atrial fibrillation & 0.248 & $<0.001$ \\
SPAP & -0.210 & 0.001 \\
EF & 0.405 & $<0.001$ \\
Presence of moderate-to-severe TR & 0.320 & $<0.001$ \\
Presence of moderate-to-severe MR & 0.324 & $<0.001$ \\
Left atrial diameter & 0.282 & $<0.001$ \\
BUN & 0.405 & $<0.001$ \\
Creatinine & -0.194 & 0.003 \\
Hemoglobin & -0.430 & $<0.001$ \\
Sodium &
\end{tabular}

BUN: Blood urea nitrogen, LOS: Length of stay, BNP: B-type natriuretic peptide, SPAP: Systolic pulmonary artery pressure, MR: Mitral regurgitation, TR: Tricuspid regurgitation, EF: Ejection fraction

creatinine level $(\mathrm{OR}=2.658,95 \% \mathrm{CI}: 1.409-5.014, P=0.003)$, sodium level $(\mathrm{OR}=0.839,95 \% \mathrm{CI}: 0.745-0.946, P=0.004)$ remained associated with longer LOS after adjustment for age, gender and for the variables found to be statistically significant in univariate analysis and correlated with LOS. 


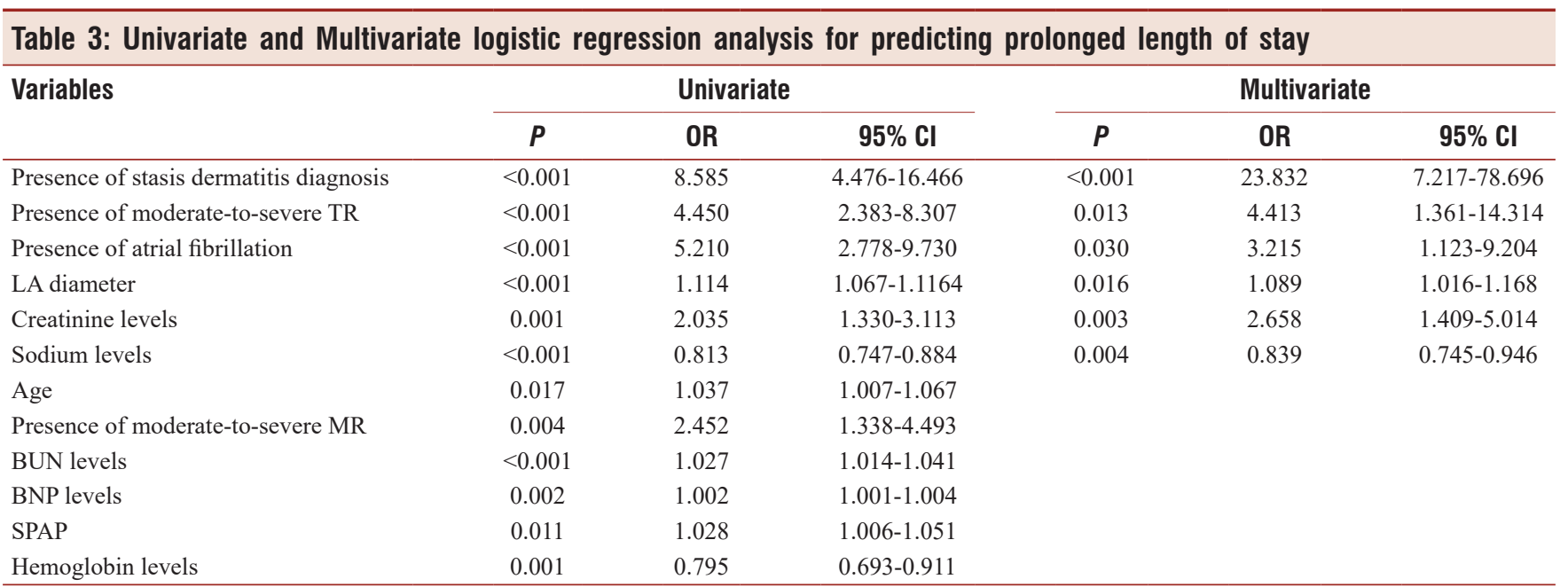

All the variables from Table 1 were examined, and only those significant at $P<0.05$ level and correlated with LOS are shown in univarite analysis. Multivariate logistic regression, including all the variables in univariate analysis with forward stepwise method. CI: Confidence interval, OR: Odds ratio, BUN: Blood urea nitrogen, LOS: Length of stay, BNP: B-type natriuretic peptide, SPAP: Systolic pulmonary artery pressure, MR: Mitral regurgitation, TR: Tricuspid regurgitation, LA: Left atrial

\section{Discussion}

To the best of our knowledge, for the first time in the literature, we illustrated that the presence of SD diagnosis is independently associated with prolonged LOS in patients hospitalized with ADHF.

Hospitalizations related to HF, which are increasing worldwide, pose a significant burden in terms of health expenditures. During hospitalizations due to HF, the rise of LOS due to various reasons increases additional clinical problems such as hyponatremia, hypokalemia, anemia, embolic and hemorrhagic complications, hospital infections in patients, and these clinical problems also lead to longer LOS. It creates a vicious cycle, leading to both an increase in morbidity and mortality rates in patients and a further increase in health-care costs. ${ }^{[12-16]}$ Determining the factors associated with prolonged LOS in HF patients may contribute to the solution of this problem, which causes both clinical and economic problems.

To date, it has been determined that many different parameters have been associated with LOS in studies conducted at different centers which evaluated the factors associated with the LOS in HF patients. It has been shown that chronic kidney disease (CKD), chronic obstructive pulmonary disease, DM, severe MR, the presence of $\mathrm{AF}$, low systolic blood pressure, high pulse rate, low hemoglobin, low sodium, high creatinine, and higher $\mathrm{BN} P$ values are associated with longer LOS. ${ }^{[17-20]}$ In our study, the presence of $\mathrm{AF}$, higher creatinine, and lower sodium values were associated with prolonged LOS independently of other variables, which are overlapping with the other studies ${ }^{[13,20]}$ Higher BNP, higher BUN, lower hemoglobin value, and severe MR, which were found significant in other studies through multivariate analysis, were determined significant in the univariate analysis of our study, while it lost its significance in the multivariate analysis. ${ }^{[13,18]}$ In addition, in the subgroup analysis of the recently published multicenter study Journey HF-TR, New York Heart Association functional capacity, CKD, ACS-related HF, right HF, cardiogenic shock, invasive and noninvasive ventilation, and hemodynamic monitorization were found independently associated with prolonged LOS. ${ }^{[4]}$ In our study, unlike Sinan et al., HF patients associated with ACS and cardiogenic shock patients, who are thought to have long LOS due to their clinical condition, were not included in the study. Although the right HF patients are also not specified in our study, the presence of moderate-severe TR, which we can consider as an echocardiographic parameter that is indirectly associated with right heart functions, was found to be independently associated with prolonged LOS. Again, in our study, higher creatinine values were found to be independently associated with prolonged LOS, which is in line with the Journey HF TR study. ${ }^{[4]}$

With the increase of venous pressure in the lower extremities in the SD, venous valves in these veins remain insufficient, resulting in reflux current in the direction of gravity leading to accumulation in the lower extremity; thus, it is thought that the inflation caused by increased hydrostatic pressure in these veins of the region leads to changes in the skin. ${ }^{[21]}$ The venous pressure increase in these veins may be caused by the insufficiency of primary valves of veins or the insufficiency of valves due to trauma, deep vein thrombosis, as well as can also be caused by venous valves, which become insufficient due to increased hydrostatic pressure in lower extremities depending on the increased right heart pressures caused by HF, especially right HF. ${ }^{[21,22]}$ Thus, the patients with venous insufficiency or deep vein thrombosis were excluded from the study.

It has been known long ago that venous congestion has an effect on renal function. Decreased transrenal pressure gradient as a result of increased venous pressure in HF patients has been shown to be associated with impaired renal function and inadequate response to diuretic therapy. ${ }^{[23-25]}$ In a study of the left and right heart pressures in hospitalized HF patients, 
central venous pressure (CVP) was shown to be the most important predictor of worsening renal function. ${ }^{[26]}$ The clinical indication of renal venous pressure increase can be considered as the development of peripheral edema and CVP increase. In a study covering 12,778 patients, Chen et al. showed that the increase in peripheral edema and CVP was associated with the severity of impaired renal function. ${ }^{[27]}$ The congestion, which is the most important cause of recurrent hospitalization in HF patients, has been shown to shorten the length of time to the rehospitalization and increase mortality when it does not decline sufficiently during hospitalization. ${ }^{[28-30]}$ In our study, when the development pathogenesis of SD is considered, venous HT, which leads to the development of SD and developed as a result of venous congestion, can be associated with increased CVP and decreased transrenal pressure gradient. Impaired renal functions due to renal venous congestion and increased $\mathrm{CV} P$ values, as well as decreased diuretic response, can be considered a valid reason for prolonged LOS in HF patients with $\mathrm{SD} .{ }^{[23-30]}$

$\mathrm{AF}$, moderate-severe $\mathrm{TR}$, higher LA diameter and lower sodium values, which were found in this study to be associated with prolonged LOS except for SD and impaired renal functions, were also shown in previous studies to be associated with congestive HF. ${ }^{[1-35]}$ In addition, AF and lower sodium values from these parameters are independently associated with prolonged LOS, which is consistent with previous study results. ${ }^{[13,20]}$

\section{Conclusion}

The incidence rate of SD which is thought to develop as a result of venous congestion and is a common impairment encountered in hospitalized HF patients, and the relationship of SD with LOS were evaluated for the first time in the literature by our study, and the presence of SD diagnosis was found to be associated with prolonged LOS. If our study is supported by more extensive and prospective studies, it may contribute to reducing LOS and, therefore, hospital costs by formerly identifying patients with resistant congestion and associated prolonged LOS periods and by arranging appropriate treatment strategy from the outset.

\section{Our study has several limitations}

First of all, our study is a retrospective and single-centered study, and information about patients was obtained from hospital registries. Hence, unfortunately, some data are not available. Although the drugs used by the patients prior to admission are known, the treatment during hospitalization and especially the fact that the diuretic dose could not be included in the study are also important limitations. In addition, the absence of TAPSE data for the evaluation of the right heart function can also be considered among the major limitations.

\section{Financial support and sponsorship}

Nil.

\section{Conflicts of interest}

There are no conflicts of interest.

\section{REFERENCES}

1. Bui AL, Horwich TB, Fonarow GC. Epidemiology and risk profile of heart failure. Nat Rev Cardiol 2011;8:30-41.

2. Felker GM, Adams KF Jr., Konstam MA, O'Connor CM, Gheorghiade M. The problem of decompensated heart failure: Nomenclature, classification, and risk stratification. Am Heart J 2003;145:S18-25.

3. Go AS, Mozaffarian D, Roger VL, Benjamin EJ, Berry JD, Borden WB, et al. Executive summary: Heart disease and stroke statistics-2013 update: A report from the American Heart Association. Circulation 2013;127:143-52.

4. Sinan UY, Erturk M, Yıldırım E, Koçyiğit D, Karaca I, Ertas F, et al. The predictors of long-term hospitalization in Turkish heart failure population: A subgroup analysis of journey heart failure-TR study: On behalf of journey heart failure-TR investigators. Int J Cardiovasc Acad 2018;4:82-5.

5. Ni H, Nauman DJ, Hershberger RE. Managed care and outcomes of hospitalization among elderly patients with congestive heart failure. Arch Intern Med 1998;158:1231-6.

6. Sundaresan S, Migden MR, Silapunt S. Stasis dermatitis: Pathophysiology, evaluation, and management. Am J Clin Dermatol 2017;18:383-90.

7. Nieminen MS, Böhm M, Cowie MR, Drexler H, Filippatos GS, Jondeau G, et al. Executive summary of the guidelines on the diagnosis and treatment of acute heart failure: The Task Force on Acute Heart Failure of the European Society of Cardiology. Eur Heart J 2005;26:384-416.

8. Dickstein K, Cohen-Solal A, Filippatos G, McMurray JJ, Ponikowski P, Poole-Wilson PA, et al. ESC Committee for Practice Guidelines (CPG). ESC Guidelines for the diagnosis and treatment of acute and chronic heart failure 2008: The Task Force for the Diagnosis and Treatment of Acute and Chronic Heart Failure 2008 of the European Society of Cardiology. Developed in collaboration with the Heart Failure Association of the ESC (HFA) and endorsed by the European Society of Intensive Care Medicine (ESICM). Eur Heart J 2008;29:2388-442.

9. Weaver J, Billings SD. Initial presentation of stasis dermatitis mimicking solitary lesions: A previously unrecognized clinical scenario. J Am Acad Dermatol 2009;61:1028-32.

10. Lang RM, Bierig M, Devereux RB, Flachskampf FA, Foster E, Pellikka PA, et al. American Society of Echocardiography's Nomenclature and Standards Committee; Task Force on Chamber Quantification; American College of Cardiology Echocardiography Committee; American Heart Association; European Association of Echocardiography, European Society of Cardiology. Recommendations for chamber quantification. Eur J Echocardiogr 2006;7:79-108.

11. Lancellotti P, Moura L, Pierard LA, Agricola E, Popescu BA, Tribouilloy C, et al. European Association of Echocardiography recommendations for the assessment of valvular regurgitation. Part 2: Mitral and tricuspid regurgitation (native valve disease). Eur J Echocardiogr 2010;11:307-32.

12. Whellan DJ, Greiner MA, Schulman KA, Curtis LH. Costs of inpatient care among Medicare beneficiaries with heart failure, 2001 to 2004. Circ Cardiovasc Qual Outcomes 2010;3:33-40.

13. Whellan DJ, Zhao X, Hernandez AF, Liang L, Peterson ED, Bhatt DL, et al. Predictors of hospital LOS in heart failure: Findings from get with the Guidelines. J Card Fail 2011;17:649-56.

14. Kovesdy CP, Lott EH, Lu JL, Malakauskas SM, Ma JZ, Molnar MZ, et al. Hyponatremia and mortality in patients with chronic kidney disease with and without congestive heart failure. Circulation 2012;125:677-84.

15. Bonilla-Palomas JL, Gámez-López AL, Moreno-Conde M, López-Ibáñez MC, Anguita-Sánchez M, Gallego de la Sacristana A, et al. Hypoalbuminemia in acute heart failure patients: Causes and its impact on hospital and long term mortality. A J Card Fail 2014;20:350-8.

16. Ponikowski P, Voors AA, Anker SD, Bueno H, Cleland JG, Coats AJ, et al. 2016 ESC Guidelines for the Diagnosis and Treatment of Acute and Chronic Heart Failure: The Task force for the diagnosis and treatment of acute and chronic heart failure of the European Society of Cardiology (ESC) developed with the special contribution of the Heart Failure Association (HFA) of the ESC. Eur Heart J 2016;37:2129-200. 
17. Allen LA, Smoyer Tomic KE, Wilson KL, Smith DM, Agodoa I. The inpatient experience and predictors of length of stay for patients hospitalized with systolic heart failure: Comparison by commercial, Medicaid, and Medicare payer type. J Med Econ 2013;16:43-54.

18. Sahin S, Doğan U, Ozdemir K, Gök H. Evaluation of clinical and demographic characteristics and their association with length of hospital stay in patients admitted to cardiac intensive care unit with the diagnosis of acute heart failure. Anadolu Kardiyol Derg 2012;12:123-31.

19. Formiga F, Chivite D, Manito N, Mestre AR, Llopis F, Pujol R. Admission characteristics predicting longer length of stay among elderly patients hospitalized for decompensated heart failure. Eur J Intern Med 2008:19:198-202.

20. Castro GP, Verdejo PH, Vukasovic RJ, Garcés E, González I; Grupo ICARO. Predictors of hospital death and prolonged hospitalization in patients with cardiac failure in Chilean hospitals. Rev Med Chil 2006;134:1083-91.

21. Bergan JJ, Schmid-Schönbein GW, Smith PD, Nicolaides AN, Boisseau MR, Eklof B. Chronic venous disease. N Engl J Med 2006;355:488-98.

22. Sippel K, Mayer D, Ballmer B, Dragieva G, Läuchli S, French LE, et al. Evidence that venous hypertension causes stasis dermatitis. Phlebology 2011;26:361-5.

23. Testani JM, Khera AV, St. John Sutton MG, Keane MG, Wiegers SE, Shannon RP, et al. Effect of right ventricular function and venous congestion on cardiorenal interactions during the treatment of decompensated heart failure. Am J Cardiol 2010;105:511-6.

24. Whaley-Connell A, Sowers JR. Basic science: Pathophysiology: The cardiorenal metabolic syndrome. J Am Soc Hypertens 2014;8:604-6.

25. Haddad F, Doyle R, Murphy DJ, Hunt SA. Right ventricular function in cardiovascular disease, part II: Pathophysiology, clinical importance, and management of right ventricular failure. Circulation 2008;117:1717-31.

26. Mullens W, Abrahams Z, Francis GS, Sokos G, Taylor DO, Starling RC, et al. Importance of venous congestion for worsening of renal function in advanced decompensated heart failure. J Am Coll Cardiol 2009;53:589-96.

27. Chen KP, Cavender S, Lee J, Feng M, Mark RG, Celi LA, et al.
Peripheral edema, central venous pressure, and risk of AKI in critical illness. Clin J Am Soc Nephrol 2016;11:602-8.

28. O’Connor CM, Stough WG, Gallup DS, Hasselblad V, Gheorghiade M. Demographics, clinical characteristics, and outcomes of patients hospitalized for decompensated heart failure: Observations from the IMPACT-HF registry. J Card Fail 2005;11:200-5.

29. Ambrosy AP, Pang PS, Khan S, Konstam MA, Fonarow GC, Traver B, et al. Clinical course and predictive value of congestion during hospitalization in patients admitted for worsening signs and symptoms of heart failure with reduced ejection fraction: Findings from the EVEREST trial. Eur Heart J 2013;34:835-43.

30. Lala A, McNulty SE, Mentz RJ, Dunlay SM, Vader JM, AbouEzzeddine OF, et al. Relief and recurrence of congestion during and after hospitalization for acute heart failure: Insights from diuretic optimization strategy evaluation in acute decompensated heart failure (DOSE-AHF) and cardiorenal rescue study in acute decompensated heart failure (CARESS-HF). Circ Heart Fail 2015;8:741-8

31. Agricola E, Marini C, Stella S, Monello A, Fisicaro A, Tufaro V, et al. Effects of functional tricuspid regurgitation on renal function and long-term prognosis in patients with heart failure. J Cardiovasc Med (Hagerstown) 2017;18:60-8.

32. Bansal N, Fan D, Hsu CY, Ordonez JD, Marcus GM, Go AS. Incident atrial fibrillation and risk of end-stage renal disease in adults with chronic kidney disease. Circulation 2013;127:569-74.

33. Kobayashi M, Huttin O, Donal E, Duarte K, Hubert A, Le Breton H, et al. Association of estimated plasma volume status with hemodynamic and echocardiographic parameters. Clin Res Cardiol 2020. doi: 10.1007/ s00392-020-01599-9. [Epub ahead of print].

34. Kitai T, Grodin JL, Kim YH, Tang WH. Impact of ultrafiltration on serum sodium homeostasis and its clinical implication in patients with acute heart failure, congestion, and worsening renal function. Circ Heart Fail 2017;10:e003603.

35. Omar HR, Guglin M. Longer-than-average length of stay in acute heart failure: Determinants and outcomes. Herz 2018;43:131-9. 